\title{
Electrodeposition and Characterization of Nanocrystalline Ni-B with Low Boron Content for MEMS Applications
}

\author{
Hong-Beom Kwon, KyongTae Kim, Hye-Rin Ahn, and Yong-Jun Kim* \\ School of Mechanical Engineering, Yonsei University, \\ 134 Shinchon-dong, Seodaemun-gu, Seoul 120-749, Korea
}

(Received August 1, 2016; accepted November 15, 2016)

Keywords: nanocrystalline Ni-B, MEMS application, electrodeposition, thermal stability, hardness, elastic modulus

We fabricated and characterized three kinds of nanocrystalline (NC) Ni-B electrodeposits with low boron content (i.e., 0.05, 0.12, and $0.19 \mathrm{wt} \%$ ) for micro-electromechanical system (MEMS) applications. The fabrication was performed by electrodeposition in a nickel sulfamate solution, adjusting the concentration of the boron source, dimethyleamine borane (DMAB). The electrodeposits exhibited high thermal stability, being able to maintain their grain size at $573 \mathrm{~K}$, whereas pure $\mathrm{NC} \mathrm{Ni}$ started recrystallizing at $473 \mathrm{~K}$. This can be explained by the formation of $\mathrm{Ni}_{x} \mathrm{~B}$ precipitators in the nickel matrix, which then migrate to the grain boundary region and effectively impede grain growth at high temperatures. Furthermore, the mechanical properties of $\mathrm{NC} \mathrm{Ni}-\mathrm{B}$ electrodeposits were significantly enhanced and they exhibited excellent mechanical performance. The hardness and elastic modulus of $\mathrm{Ni}-0.19 \mathrm{~B}$ with $573 \mathrm{~K}$ heat treatment are 251.4 and 12.6 GPa, respectively, which are much higher than those of pure NC Ni. These outstanding properties show the potential applicability of $\mathrm{NC} \mathrm{Ni-B}$ electrodeposits as microgears, micocantilevers, microactuators, and MEMS probe cards, which require high mechanical performance and thermal stability.

\section{Introduction}

Considerable attention has been paid to nanocrystalline (NC) Ni electrodeposits as prospective candidates for micro-electromechanical system (MEMS) components, especially applications that require high mechanical performance. ${ }^{(1-3)}$ Indeed, reducing the grain size to below $100 \mathrm{~nm}$ not only leads to a significant enhancement in the mechanical properties compared with those of conventional coarse-grained $\mathrm{Ni}$, according to the well-known Hall-Petch relationship, ${ }^{(4,5)}$ but can also offer isotropic mechanical properties even in micrometer-sized components.

However, despite these outstanding mechanical properties, NC Ni electrodeposits typically exhibit low thermal stability. ${ }^{(6,7)}$ They start recrystallizing rapidly and lose their mechanical properties at relatively low temperatures. For instance, the abnormal grain growth of $\mathrm{NC} \mathrm{Ni}$ electrodeposits can be observed under thermal exposure at $473 \mathrm{~K}$ for $2 \mathrm{~h} \cdot{ }^{(8)}$ Poor thermal stability is a major limitation when applying NC Ni electrodeposits to MEMS devices, which require various 
heating steps to manufacture and are vulnerable to localized temperature increments, caused by electrical Joule heating, during operation.

Alloying is one of the promising techniques for improving the microstructure stability of NC Ni electrodeposits at elevated temperatures. ${ }^{(9,10)}$ Alloying elements reduce the driving force of grain growth by segregation to the grain boundary region and/or by forming second phase precipitators. On the basis of these mechanisms, a variety of NC Ni-based alloys (e.g., Ni-W, Ni$\mathrm{P}, \mathrm{Ni}-\mathrm{Cu}, \mathrm{Ni}-\mathrm{Fe}$, and $\mathrm{Ni}-\mathrm{Co}$, etc.) have been shown to enhance the thermal stability of $\mathrm{NC} \mathrm{Ni}$ electrodeposits. ${ }^{(6,8,9,11-14)}$

In particular, $\mathrm{NC} \mathrm{Ni-B} \mathrm{electrodeposits} \mathrm{maintain} \mathrm{the} \mathrm{high} \mathrm{thermal} \mathrm{stability} \mathrm{of} \mathrm{the} \mathrm{aforementioned}$ Ni alloys. Moreover, it has been reported that the incorporation of boron further enhances the hardness and creep resistance of $\mathrm{NC} \mathrm{Ni.}{ }^{(15)}$ However, previous studies on $\mathrm{NC} \mathrm{Ni-B} \mathrm{have} \mathrm{been}$ mainly focused on plating with a large amount of boron solely to enhance the wear resistance of the surface coating. ${ }^{(16-19)}$ Excessive addition of boron reduces the grain size excessively, increasing the amorphous fraction and thus leading to an inverse Hall-Petch relationship, i.e., an abrupt decrease in hardness, yield strength, and tensile strength as a result of a change in the deformation mechanism. ${ }^{(20)}$ In addition, it was determined that the residual stress of $\mathrm{NC} \mathrm{Ni-B} \mathrm{electrodeposits} \mathrm{increases} \mathrm{with} \mathrm{the}$ increase in boron content, ${ }^{(18)}$ which results in the reduced reliability of MEMS components.

In this study, $\mathrm{NC} \mathrm{Ni-B} \mathrm{electrodeposits} \mathrm{with} \mathrm{low} \mathrm{boron} \mathrm{content} \mathrm{were} \mathrm{fabricated} \mathrm{and} \mathrm{characterized.}$ Because of low residual stress, NC Ni-B electrodeposits could be successfully deposited over 60 $\mu \mathrm{m}$ without any deformation. It was found that even adding a small amount of boron enhanced the thermal stability of $\mathrm{NC} \mathrm{Ni}-\mathrm{B}$ electrodeposits because $\mathrm{Ni}_{x} \mathrm{~B}$ precipitators were formed during heat treatment and effectively suppress grain growth. In addition, the hardness and elastic modulus of $\mathrm{NC} \mathrm{Ni}-\mathrm{B}$ electrodeposits were markedly improved compared with those of pure NC Ni. Thus, these results show the potential applicability of the proposed $\mathrm{NC} \mathrm{Ni-B}$ electrodeposits to MEMS devices.

\section{Materials and Methods}

\subsection{Fabrication}

Silicon (100) wafers of 4 inch diameter were used as substrates. A seed layer consisting of a Ti/ $\mathrm{Cu}(50 \mathrm{~nm} / 500 \mathrm{~nm})$ film was deposited on the wafers by E-beam evaporation. Then, the negative tone photoresist JSR THB-151N was spin-coated. Finally, soft baking, UV-light exposure, and a developing procedure were carried out successively.

After finishing the photolithographic process, $\mathrm{NC} \mathrm{Ni-B} \mathrm{was} \mathrm{electrodeposited} \mathrm{from} \mathrm{a} \mathrm{nickel}$ sulfamate solution containing $400 \mathrm{~g} / \mathrm{L} \mathrm{Ni}\left(\mathrm{SO}_{3} \mathrm{NH}_{2}\right)_{2} \cdot 4 \mathrm{H}_{2} \mathrm{O}$ (nickel sulfamate), $10 \mathrm{~g} / \mathrm{L} \mathrm{NiCl}{ }_{2} \cdot 6 \mathrm{H}_{2} \mathrm{O}$ (nickel chloride), $40 \mathrm{~g} / \mathrm{L} \mathrm{H}_{3} \mathrm{BO}_{3}$ (boric acid), $0.25 \mathrm{~g} / \mathrm{L} \mathrm{CH}_{3}\left(\mathrm{CH}_{2}\right)_{11} \mathrm{OSO}_{3} \mathrm{Na}$ (sodium dodecyl sulfate), $0.048 \mathrm{~g} / \mathrm{L} \mathrm{C}_{7} \mathrm{H}_{4} \mathrm{NNaO}_{3} \mathrm{~S} \cdot 2 \mathrm{H}_{2} \mathrm{O}$ (saccharin) as a stress reducer, and 0 to $0.09 \mathrm{~g} / \mathrm{L}\left(\mathrm{CH}_{3}\right)_{2} \mathrm{NH} \cdot \mathrm{BH}_{3}$ (dimethylamine borane; DMAB) as a boron source. All chemicals used were acquired from SigmaAldrich. A titanium basket containing sulfur-depolarized Ni pellets was used as a counter electrode. The $\mathrm{pH}$ of the solution was adjusted to 4.0 using sulfamic acid $\left(\mathrm{H}_{3} \mathrm{NSO}_{3}\right)$ and sodium hydroxide $(\mathrm{NaOH})$. The process was performed at $50{ }^{\circ} \mathrm{C}$ with a current density of $15 \mathrm{~mA} / \mathrm{cm}^{2}$. The thickness of the electrodeposits was adjusted to about $60 \mu \mathrm{m}$ by controlling the plating time. Figure 1 shows the fabricated specimens and their uniform and smooth surface owing to grain refinement. 


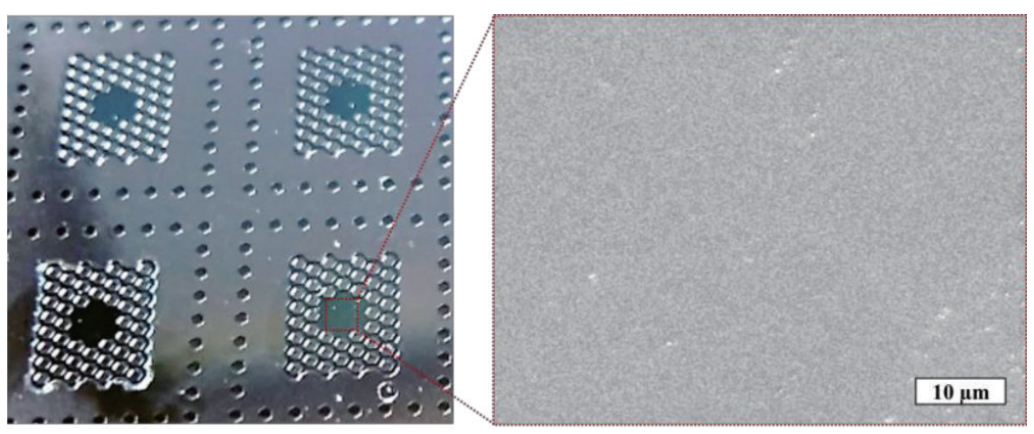

(a)

(b)

Fig. 1. (Color online) (a) Photograph of fabricated Ni-B specimens and (b) SEM image of the specimen surface.

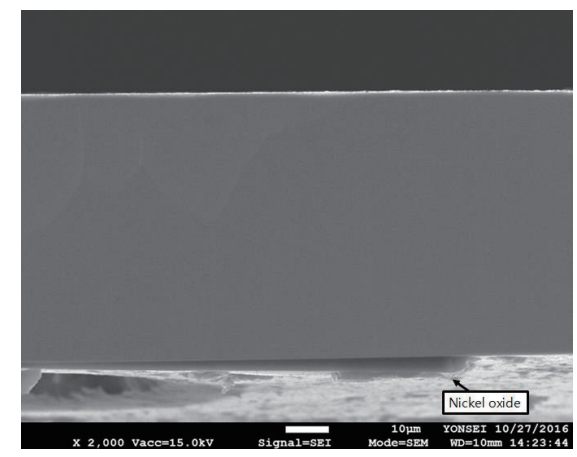

Fig. 2. Cross-sectional SEM image of the Ni-B specimen.

Moreover, there are no pores or defects inside the electrodeposits as shown in Fig. 2. The NC $\mathrm{Ni}-\mathrm{B}$ electrodeposits were heat-treated at temperatures ranging from 423 to $673 \mathrm{~K}$ for $2 \mathrm{~h}$. This procedure was performed under vacuum conditions $(50 \mathrm{mTorr})$ to prevent the surface oxidation of the electrodeposits.

\subsection{Microstructure characterization}

The average boron content of the $\mathrm{NC} \mathrm{Ni-B} \mathrm{electrodeposits} \mathrm{was} \mathrm{investigated} \mathrm{using} \mathrm{an} \mathrm{inductively}$ coupled plasma-optical emission spectrometer (ICP-OES) (ICP-OES 720, Agilent).

The microstructure of NC Ni-B electrodeposits was characterized using an X-ray diffractometer (Dmax2500/PC, Rigaku), with $\mathrm{Cu}-\mathrm{K} \alpha$ radiation at step intervals of $0.02^{\circ}(2 \theta)$ in the range of 10 to $110^{\circ}$. The average grain size was determined from calculations applying the Scherrer formula ${ }^{(21)}$ on the diffraction line broadening of the $<111>$ peak. Grains larger than $100 \mathrm{~nm}$, which could not be measured by X-ray diffraction (XRD), were estimated using scanning electron microscope-electron backscatter diffraction (SEM-EBSD) (MERLIN, Carl Zeiss).

\subsection{Hardness and elastic modulus characterization}

The nanoindentation tests were performed by using a nanoindenter (G200, Agilent) with a Berkovich tip. The maximum applied force was set at $20 \mathrm{mN}$ with a loading and unloading rate of $500 \mu \mathrm{N} / \mathrm{s}$. The maximum force was held for $30 \mathrm{~s}$ in order to minimize the creeping effect on the 
unloading step, thus obtaining reliable data. The Oliver-Pharr method was used to determine the elastic modulus and hardness from indentation load-displacement curves (see Fig. 3).(22)

The hardness $H$ was determined using

$$
H_{\max }=\frac{P_{\max }}{A_{c}}
$$

where $P_{\max }$ is the maximum load and $A_{c}$ is the projected contact area. The effective elastic modulus $E_{\text {eff }}$ was determined as

$$
E_{\text {eff }}=\left.\frac{1}{2}\left(\frac{\pi}{A_{c}}\right)^{\frac{1}{2}} \frac{d P}{d h}\right|_{h=h_{\max }},
$$

where $h_{\max }$ is the maximum displacement and $d P / d h$ is the contact stiffness corresponding to the slope of the unloading curve at the beginning. The elastic modulus $E$ is obtained as

$$
\frac{1}{E_{\text {eff }}}=\frac{1-v^{2}}{E}+\frac{1-v_{i}^{2}}{E}
$$

where $E_{i}=1141 \mathrm{GPa}, v_{i}=0.07$ for Berkovich indenters, and $v=0.3$ for $\mathrm{NC} \mathrm{Ni-B}$ electrodeposits.

\section{Results and Discussion}

\subsection{Microstructure}

Figure 4 shows the XRD patterns of the pure $\mathrm{NC} \mathrm{Ni}$ and as-plated $\mathrm{NC} \mathrm{Ni-B}$ electrodeposits. It can be observed that the preferred orientation of the NC Ni-B electrodeposits changed from $<200>$ to $<111>$ with increasing boron content. Regarding the effect of the texture on the NC Ni-based

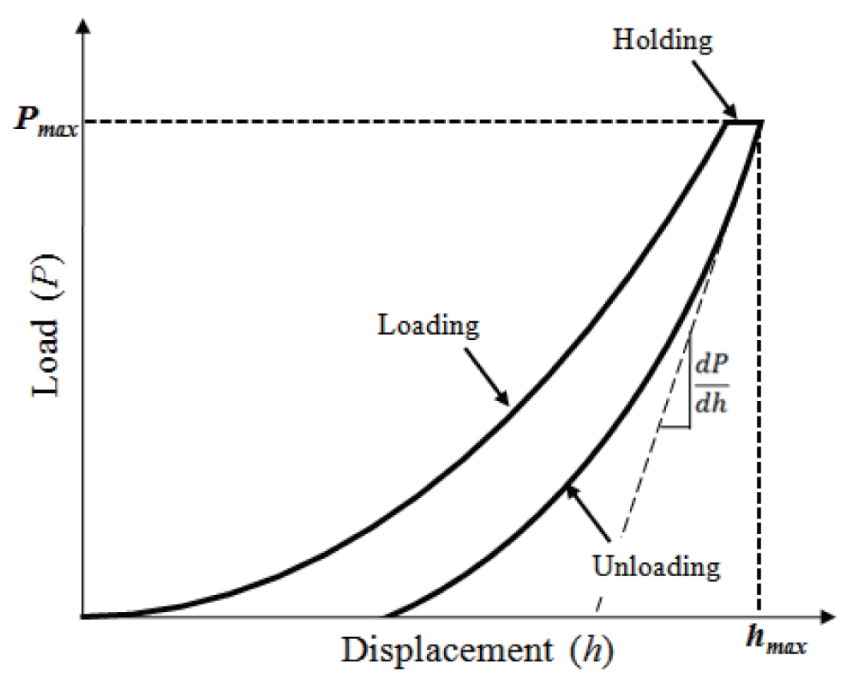

Fig. 3. Schematic diagram of a typical indentation load-displacement curve. 


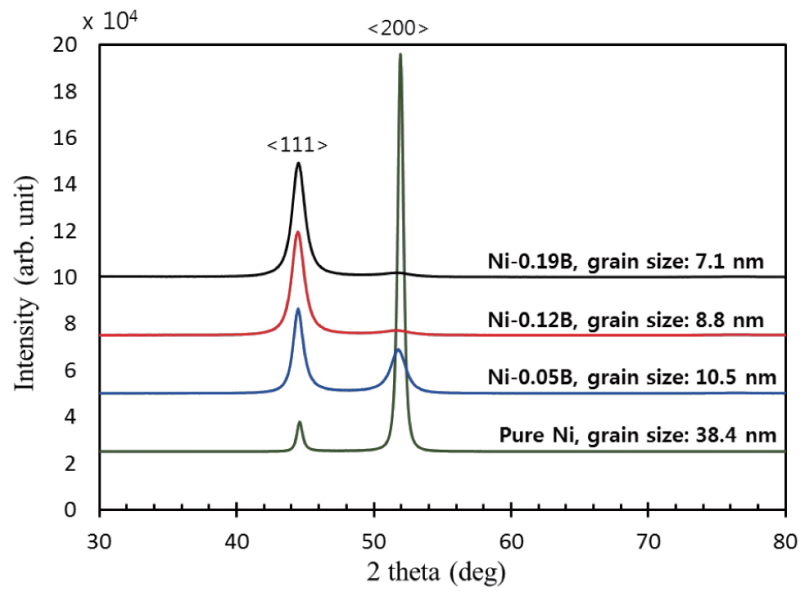

Fig. 4. (Color online) XRD patterns of pure $\mathrm{NC} \mathrm{Ni}$ and $\mathrm{NC} \mathrm{Ni-B} \mathrm{electrodeposits.}$

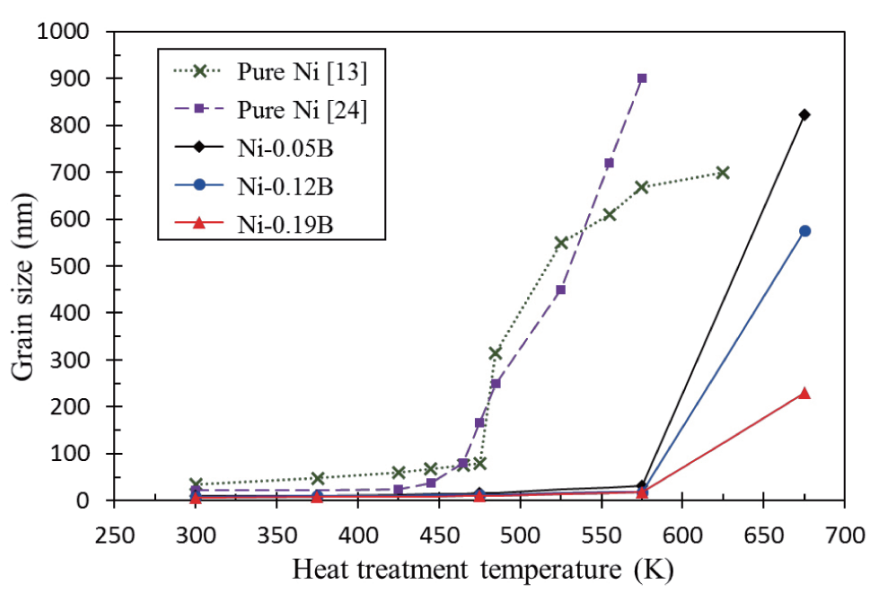

Fig. 5. (Color online) Variation in grain size as a function of heat treatment temperature for pure $\mathrm{NC}$ $\mathrm{Ni}$ and $\mathrm{NC} \mathrm{Ni}-\mathrm{B}$ electrodeposits.

material hardness, it has been reported that nickel with $<111>$ orientation has higher hardness than that of other planes. ${ }^{(23)}$

The grain size of pure NC Ni is $38.4 \mathrm{~nm}$ because saccharin, which is used as a stress reliever, also plays a role in grain refinement. Moreover, boron effectively retards the grain growth of nickel during the electrodeposition process. Adding a small amount of boron $(0.05 \mathrm{wt} . \%)$ reduces the grain size to $10.5 \mathrm{~nm}$. The average grain sizes of $\mathrm{Ni}-0.12 \mathrm{~B}$ and $\mathrm{Ni}-0.19 \mathrm{~B}$ are 8.8 and $7.1 \mathrm{~nm}$, respectively, which are slightly below the lower limit of the Hall-Petch relationship (10 nm). Further grain size reduction could lead to severe degradation of the mechanical performance. Therefore, the boron content should be below 0.19 wt.\% for the proposed electrodeposition conditions.

\subsection{Thermal stability}

Figure 5 shows the grain size of pure $\mathrm{NC} \mathrm{Ni}$ and $\mathrm{NC} \mathrm{Ni-B}$ electrodeposits as a function of heat treatment temperature. The grain size of $\mathrm{NC} \mathrm{Ni-B}$ electrodeposits remained below $100 \mathrm{~nm}$ at $573 \mathrm{~K}$ regardless of the boron content, whereas abnormal grain growth occurred in pure $\mathrm{NC} \mathrm{Ni}$ at around $473 \mathrm{~K} \cdot{ }^{(13,24)}$ These results show that, in terms of micromorphology, alloying nickel with boron significantly enhances the thermal stability of $\mathrm{NC} \mathrm{Ni}$.

To better understand the high thermal stability of NC Ni-B electrodeposits, SEM-ESBD images were taken after heat treatment at $673 \mathrm{~K}$ (Fig. 6). $\mathrm{Ni}_{x} \mathrm{~B}$ precipitators are depicted as red dots. The results suggest that boron significantly influences the grain growth during heat treatment. The average grain size of the $\mathrm{Ni}-\mathrm{B}$ electrodeposits decreased from 0.82 to $0.23 \mu \mathrm{m}$ as the boron content increased from 0.05 to $0.19 \mathrm{wt} . \%$. In addition, $\mathrm{Ni}-0.19 \mathrm{~B}$ had the narrow grain size distribution, while the grain size distribution of $\mathrm{Ni}-0.05 \mathrm{~B}$ was largely broad and even normal polycrystalline grains could be observed. These phenomena can be explained by the formation of $\mathrm{Ni}_{x} \mathrm{~B}$ precipitators and Zener drag. ${ }^{25)}$ The images show that all the $\mathrm{NC} \mathrm{Ni-B}$ electrodeposits have $\mathrm{Ni}_{x} \mathrm{~B}$ precipitators in their grain boundary regions, while the interior matrix of grains is depleted of 


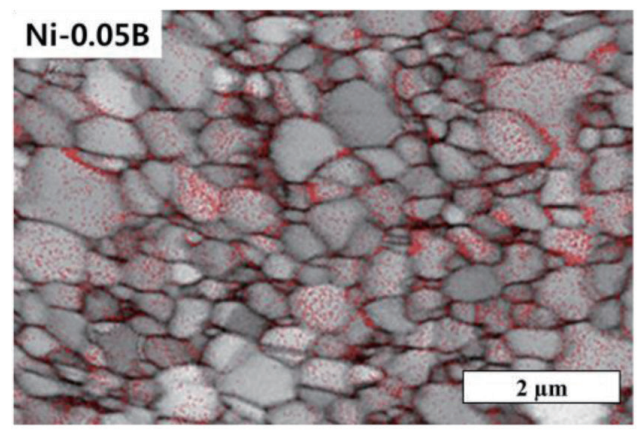

(a)

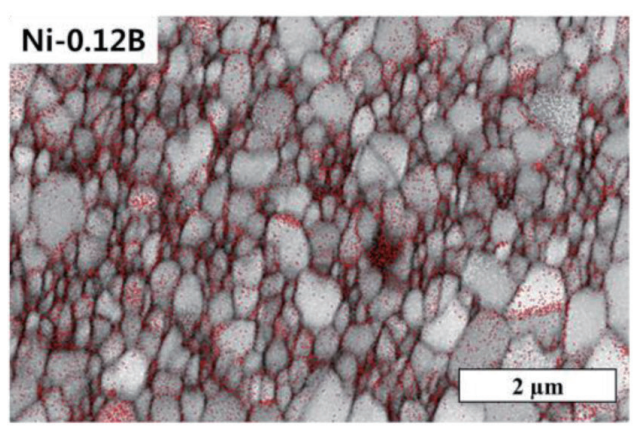

(b)

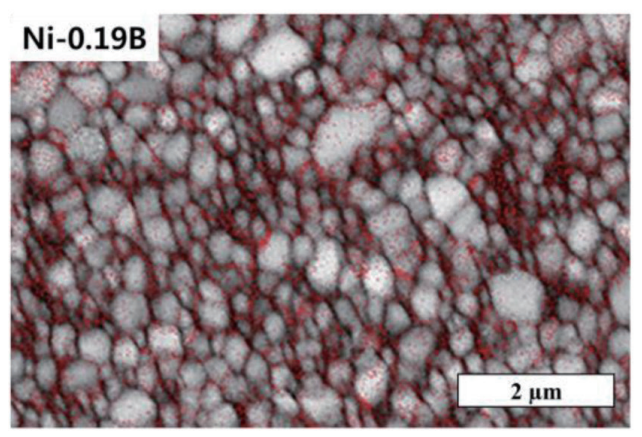

(c)

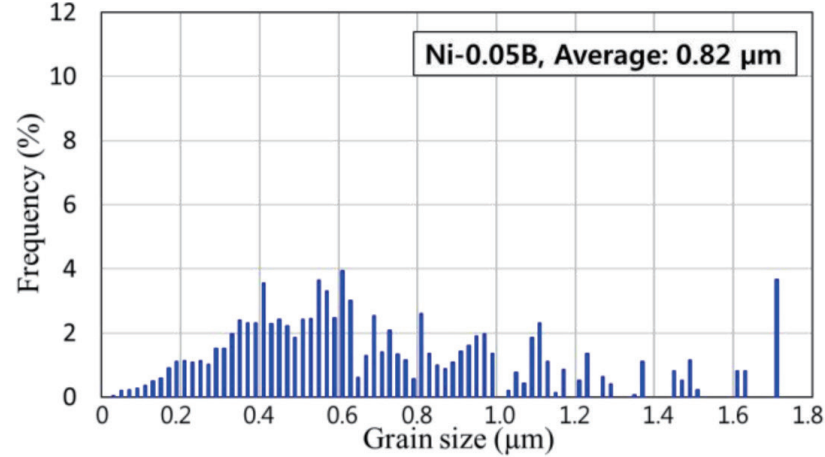

(d)

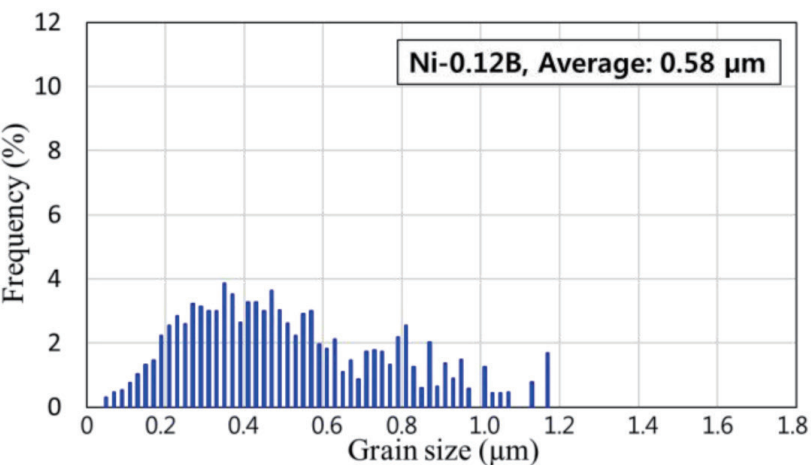

(e)

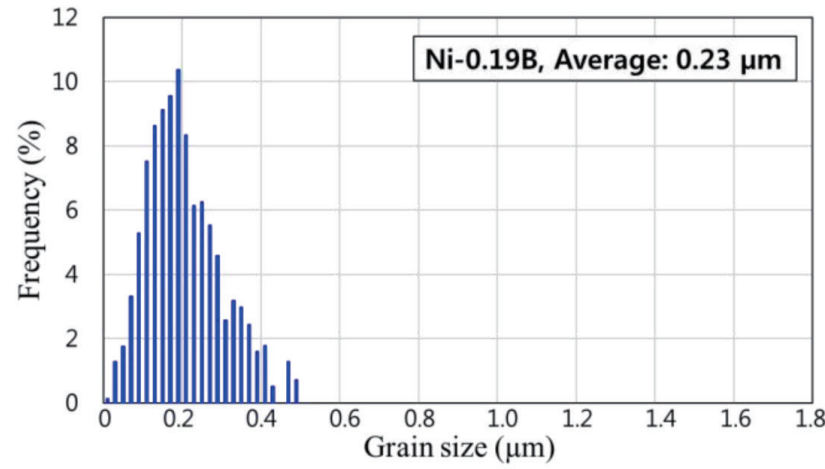

(f)

Fig. 6. (Color online) SEM-EBSD images of (a) Ni-0.05B, (b) Ni-0.12B, and (c) Ni-0.19B, and the grain size distributions of (d) Ni-0.05B, (e) Ni-0.12B, and (f) Ni-0.19B after heat treatment at $673 \mathrm{~K}$.

boron, meaning that boron migrates into the grain boundary. During heat treatment, grains acquire a driving force for grain growth, and thus their grain boundaries move forward and pass through these $\mathrm{Ni}_{x} \mathrm{~B}$ precipitators. When passing the $\mathrm{Ni}_{x} \mathrm{~B}$ precipitators, grain boundaries must increase their area as a result of attractive forces between them, requiring higher energy for further migration. Furthermore, a drag force is applied to the grains by the $\mathrm{Ni}_{x} \mathrm{~B}$ precipitators. These mechanisms cause the need for higher energy for grain boundary migration, interrupting or suppressing further grain growth at high temperatures. 


\subsection{Hardness and elastic modulus evaluated by nanoindentation}

Figure 7 shows typical load-displacement curves obtained for as-plated and heat-treated $\mathrm{NC} \mathrm{Ni-}$ $\mathrm{B}$ electrodeposits. Figure 8 shows the hardness and elastic modulus of $\mathrm{NC} \mathrm{Ni-B}$ electrodeposits with various boron contents as a function of heat treatment temperature. As shown in Fig. 8(a), the hardness value of as-plated $\mathrm{NC} \mathrm{Ni-B}$ electrodeposits is significantly enhanced with just a small addition of boron, far surpassing the $7 \mathrm{GPa}$ hardness value of NC Ni.(13) This can be explained by the grain size refinement, the high hardness value of boron, and the change in the preferred crystallographic orientation from $<200>$ to $<111>$. However, the hardness of as-plated NC Ni-B electrodeposits decreases as boron content increases. This phenomenon can be explained by the inverse Hall-Petch relationship. The grain size of as-plated NC Ni-B decreases from 10.5 to 7.1 $\mathrm{nm}$ as boron content increases from 0.05 to $0.19 \mathrm{wt} . \%$. When the grain size falls below a critical

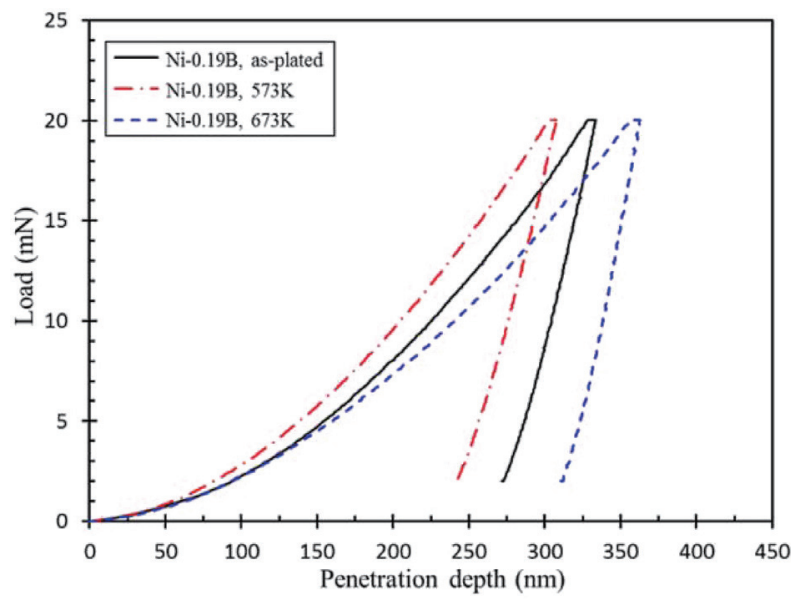

Fig. 7. (Color online) Load-displacement nanoindentation curves of $\mathrm{Ni}-0.19 \mathrm{~B}$ after heat treatment at various temperatures.

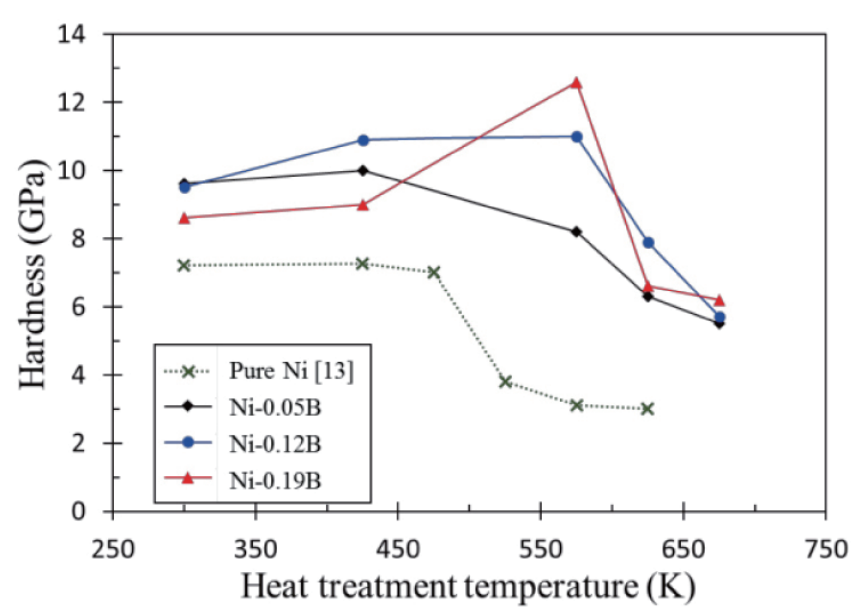

(a)

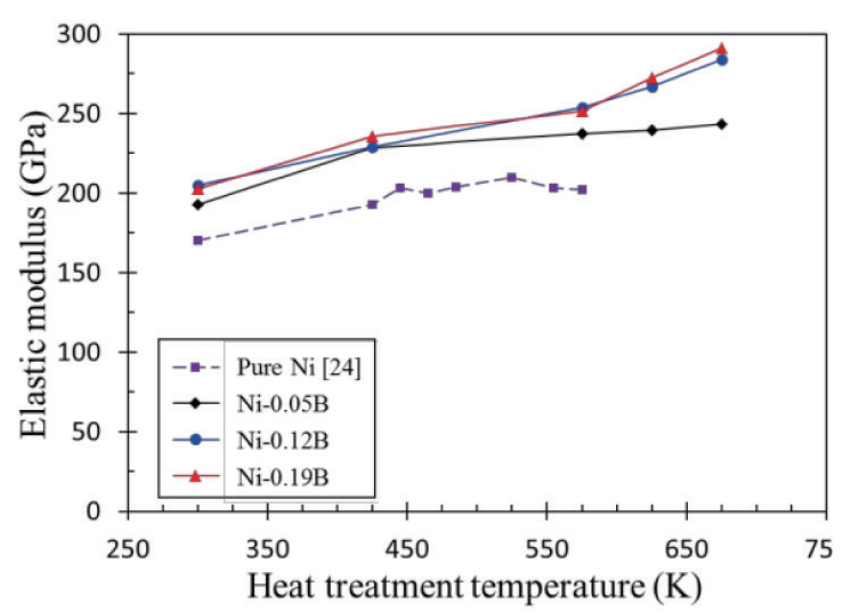

(b)

Fig. 8. (Color online) (a) Hardness and (b) elastic modulus of pure NC Ni and NC Ni-B electrodeposits as a function of heat treatment temperature. 
value (approximately $10 \mathrm{~nm}$ ), the deformation mechanism changes from dislocation-dominant deformation to grain boundary sliding deformation; this, in turn, leads to a decrease in the hardness.

The high hardness of as-plated NC Ni-B electrodeposits further increases during heat treatment. The hardness value of $\mathrm{Ni}-0.19 \mathrm{~B}$ approaches the maximum plateau of $12.61 \mathrm{GPa}$ at $573 \mathrm{~K}$. The reason for this is that $\mathrm{Ni}_{x} \mathrm{~B}$ precipitators, which are formed at around $573 \mathrm{~K}$ and migrate into the grain boundary, suppress the dislocation movement. Since dislocation is the dominant deformation mechanism in the Hall-Petch domain, this phenomenon serves to harden $\mathrm{NC} \mathrm{Ni-B}$ electrodeposits. However, $\mathrm{Ni}-0.05 \mathrm{~B}$ has lower hardness at $573 \mathrm{~K}$ than at $473 \mathrm{~K}$, since $\mathrm{Ni}-0.05 \mathrm{~B}$ has a small amount of boron and cannot make enough $\mathrm{Ni}_{x} \mathrm{~B}$ precipitators to effectively impede grain growth.

Note that adding boron increases thermal stability such that it broadens the temperature range in which $\mathrm{NC} \mathrm{Ni-B} \mathrm{electrodeposits} \mathrm{maintain} \mathrm{high} \mathrm{hardness} \mathrm{values.} \mathrm{While} \mathrm{the} \mathrm{hardness} \mathrm{value} \mathrm{of} \mathrm{pure}$ $\mathrm{NC}$ Ni abruptly decreases above the heat treatment temperature of $473 \mathrm{~K}, \mathrm{NC} \mathrm{Ni}-\mathrm{B}$ electrodeposits maintain their mechanical properties at $573 \mathrm{~K}$.

As shown in Fig. 8(b), the elastic modulus of the as-plated NC Ni-B electrodeposits is around $200 \mathrm{GPa}$, which is similar to those of pure NC Ni and conventional polycrystalline Ni found in the literature. ${ }^{(24,26)}$ However, as the heat treatment temperature increases, the elastic modulus of $\mathrm{Ni}-\mathrm{B}$ electrodeposits is found to significantly increase regardless of the boron content, while the elastic modulus of pure NC Ni remains at a similar value. The maximum value of the elastic modulus is 291.4 GPa for $\mathrm{Ni}-0.19 \mathrm{~B}$ electrodeposits heat treated at $673 \mathrm{~K}$. Although it is speculated that $\mathrm{Ni}_{x} \mathrm{~B}$ precipitators increase the elastic modulus, because they are migrated into the grain boundary region and hinder the grain boundary movement, further research should be conducted to identify the exact mechanism of this increase.

\section{Conclusions}

In this study, we successfully fabricated $\mathrm{NC} \mathrm{Ni-B} \mathrm{with} \mathrm{low} \mathrm{boron} \mathrm{content} \mathrm{and} \mathrm{a} \mathrm{thickness} \mathrm{of}$ $60 \mu \mathrm{m}$ by electrodeposition. The thermal stability of pure NC Ni is significantly enhanced by introducing boron into the nickel matrix, because, at high temperatures, $\mathrm{Ni}_{x} \mathrm{~B}$ precipitators are formed, retarding grain growth. $\mathrm{NC} \mathrm{Ni-B}$ electrodeposits maintain their grain size at $573 \mathrm{~K}$, while pure $\mathrm{NC} \mathrm{Ni}$ starts to recrystallize at $473 \mathrm{~K}$. In addition, $\mathrm{NC} \mathrm{Ni-B}$ electrodeposits exhibit outstanding mechanical properties as a result of grain size reduction, the change in the preferred crystallographic orientation from $<200>$ to $<111>$, and the segregation of $\mathrm{Ni}_{x} \mathrm{~B}$ precipitators into grain boundary region. The hardness and elastic modulus of $\mathrm{Ni}-0.19 \mathrm{~B}$ with $573 \mathrm{~K}$ heat treatment are 251.4 and $12.6 \mathrm{GPa}$, respectively, which are much higher than those of pure NC Ni.

Since the proposed material, nanocrystalline $\mathrm{Ni}-\mathrm{B}$, is produced using the electrodeposition technique, it can readily be used for MEMS fabrication processes. Furthermore, it should be useful for MEMS devices such as cantilevers, microgears, microactuators or MEMS probe cards, which need good mechanical properties and high thermal stability.

\section{References}

1 I. C. Choi, Y. J. Kim, M. Y. Seok, B. G. Yoo, J. Y. Kim, Y. Wang, and J. I. Jang: Int. J. Plast. 41 (2013) 53.

2 T. Nagoshi, T. F. M. Chang, S. Tatsuo, and M. Sone: Microelectron. Eng. 110 (2013) 270.

3 M. Baghbanan, U. Erb, and G. Palumbo: Phys. Status Solidi A 203 (2006) 1259.

4 J. Li and G. J. Weng: Int. J. Plast. 23 (2007) 2115. 
5 M. A. Meyers, A. Mishra, and D. J. Benson: Prog. Mater. Sci. 51 (2006) 427.

6 M. Thuvander, M. Abraham, A. Cerezo, and G. D. W. Smith: Mater. Sci. Tech. 17 (2013) 961.

7 R. A. Andrievski: J. Mater. Sci. 38 (2003) 1367.

8 E. Pellicer, A. Varea, K. M. Sivaraman, S. Pane, S. Surinach, M. D. Baro, J. Nogues, B. J. Nelson, and J. Sort: ACS Appl. Mater. Interfaces 3 (2011) 2265.

9 H. Q. Li and F. Ebrahimi: Acta Mater. 51 (2003) 3905.

10 G. D. Hibbard, U. Erb, K. T. Aust, U. Klement, and G. Palumbo: J. Metastable Nanocryst. Mater. 13 (2002) 387.

11 S. J. Suresha, M. Haj-Taieb, K. Bade, J. Aktaa, and K. J. Hemker: Scripta Mater. 63 (2010) 1141.

12 G. D. Hibbard, K. T. Aust, and U. Erb: Mater. Sci. Eng. A-Struct. 433 (2006) 195.

13 H. Natter, M. Schmelzer, and R. Hempelmann: J. Mater. Res. 13 (1998) 1186.

14 S. C. Mehta, D. A. Smith, and U. Erb: Mater. Sci. Eng. A-Struct. 204 (1995) 227.

15 J. Everhart: Engineering Properties of Nickel and Nickel Alloys (Plenum Press, New York, 1971).

16 V. Vitry, A. F. Kanta, and F. Delaunois: Surf. Coat. Technol. 206 (2011) 1879.

17 R. Oriňáková, K. Rošáková, A. Oriňák, M. Kupková, J. N. Audinot, H. N. Migeon, J. T. Andersson, and K. Koval: J. Solid State Electrochem. 15 (2010) 1159.

18 K. H. Lee, D. Chang, and S. C. Kwon: Electrochim. Acta 50 (2005) 4538.

19 Y. N. Bekish, S. K. Poznyak, L. S. Tsybulskaya, and T. V. Gaevskaya: Electrochim. Acta 55 (2010) 2223.

20 C. E. Carlton and P. J. Ferreira: Acta Mater. 55 (2007) 3749.

21 B. D. Cullity: Elements of X-Ray Diffraction, 2nd ed. (Addison-Wesley, Reading, 1978).

22 W. C. Oliver and G. M. Pharr: J. Mater. Res. 7 (1992) 1564.

23 R. Mitra, R. A. Hoffman, A. Madan, and J. R. Weertman: J. Mater. Res. 16 (2001) 1010.

24 B. Yang: Mater. Sci. Forum 683 (2011) 103.

25 E. Nes, N. Ryum, and O. Hunderi: Acta Metall. 33 (1985) 11.

26 Metals Handbook Properties and Selection: Nonferrous Alloys and Special Purpose Materials, 10th ed. (ASM International, Materials Park, Ohio, 1990) Vol. 2.

\section{About the Authors}

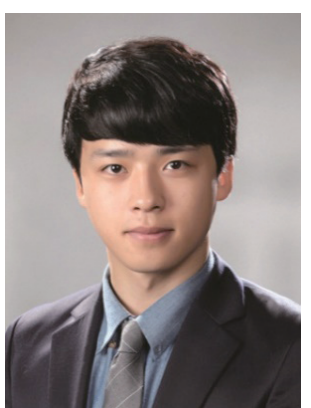

Hong-Beom Kwon received his B.S. degree from Yonsei University, Seoul, Korea, in 2013, and is currently pursuing his Ph.D. degree in mechanical engineering at the same university. His current research interests are in MEMS and sensors.

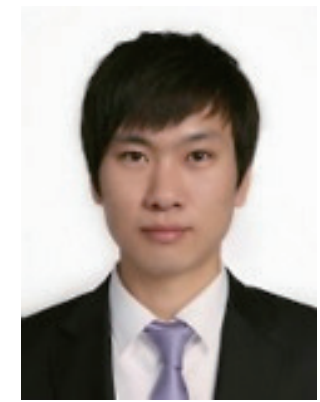

KyongTae Kim received his B.S. degree in mechanical engineering from Chosun University, Gwangju, in 2009 and his M.S. degree from Yonsei University, Seoul, Korea, in 2013. Currently, he is working toward his Ph.D. degree in mechanical engineering at Yonsei University. His research interests are in MEMS and sensors. 


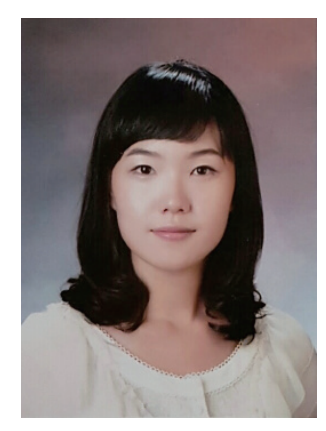

Hye-Rin Ahn received her B.S. degree in mechanical engineering from Kyungpook National University, Daegu, Korea, in 2010 and her M.S. degree from Yonsei University, Seoul, Korea, in 2012. Currently, she is pursuing her $\mathrm{Ph} . \mathrm{D}$. degree in mechanical engineering at Yonsei University, Seoul, Korea. Her current research interests are in wireless power transmission and MEMSbased sensors.

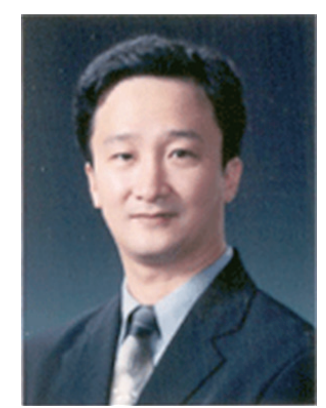

Yong-Jun Kim received his B.S. degree in electrical engineering from Yonsei University, Seoul, Korea, in 1987. His M.S. degree in electrical and computer engineering was awarded by the University of Missouri, Columbia, in 1989, and his Ph.D. degree was awarded by the Georgia Institute of Technology (Georgia Tech), Atlanta, in 1997. During his graduate studies at MissouriColumbia, he worked as a Graduate Research Assistant. The topic of his research was "Image invariants extraction algorithm using neural networks". In 1992, he joined the Microsensors and Microactuators Group, in Georgia Tech, where he conducted research as a Graduate Research Assistant. His research in micromachining includes in situ measurements of the mechanical properties of polymeric films, integrated inductors such as meander and solenoid types and their applications, and inductors for high-frequency applications. Until September 2000, he focused on the general areas of MEMS and integrated RF components and their applications at Samsung Electronics. Currently, he is a Professor in the School of Mechanical Engineering, Yonsei University. His current research includes general MEMS, integrated passives for RF or microwave applications, micromachining, and electronic packaging. 